\title{
Correction of Shading Effects on Different Components of Solar Radiation
}

\author{
Hadj Sahraoui Omar \\ Remote Sensing department, \\ Algerian Space Agency, \\ 01 Avenue de la Palestine, B.P.13 \\ Arzew, Oran, Algérie \\ sahraoui_omar1@yahoo.fr
}

\section{Chamakhi Djemoui}

Remote Sensing department, Algerian Space Agency, 01 Avenue

dchamakhi@cts.asal.dz

\author{
Fizazi Hadria \\ Computer Science department, \\ University of Sciences and \\ Technology, Oran, Algérie \\ Fizazi-hadria@univ-usto.dz
}

\author{
Berrichi Faouzi \\ Remote Sensing department, \\ Algerian Space Agency, \\ 01 Avenue de la Palestine, B.P.13 \\ Arzew, Oran, Algérie \\ fberrichi@cts.asal.dz

\section{Dif Amar} \\ Remote Sensing department, \\ Algerian Space Agency, \\ 01 Avenue de la Palestine, B.P.13 \\ Arzew, Oran, Algérie \\ adif@cts.asal.dz
}

\begin{abstract}
There have been many published articles describing shading effect algorithms for solar irradiation mapping in different components, that enabling scientists to gain experience with new techniques at low cost.
\end{abstract}

The maps for diffuse, direct and global Solar irradiation have been calculated in combination satellite image data (Input data in system) for a shorter period of one day. structured together using the "Inverse distance to a power" interpolation method.

The Global and Diffuse irradiation maps were calculated with an algorithm based for correcting shading effects related to the orography estimated in Horizontal Plane and evaluate it on any inclined plane using the sky brightness and clearness index and the relative optical attenuation factor of the atmospheric thickness. The Direct irradiation is mapped as the combination between global and diffuse irradiation. The tests of this method were carried out on several large sites, and showed good results.

Keyword: Direct and global irradiation, Diffuse circumsolar and isotropic, index of shading effect

\section{I .INTRODUCTION:}

This article describes in detail the algorithm based for correcting shading effects related to the orography.

We consider, at any point on Earth, the data at a given instant $t$ of global irradiations $\mathrm{GHI}_{\mathrm{dt}}$ and diffuse $\mathrm{DHI}_{\mathrm{dt}}$ on a horizontal plane, following an integration period between $\mathrm{t}-\mathrm{dt}$ and $\mathrm{t}$.

The direct component on horizontal plane $\mathrm{BHI}_{\mathrm{dt}}$ is deduced directly:

$$
\mathrm{BHI}_{\mathrm{dt}}=\mathrm{GHI}_{\mathrm{dt}}-\mathrm{DHI} \mathrm{dt}
$$

The direct normal incidence component BNI $\mathrm{dt}_{\mathrm{dt}}$ as a function of the solar elevation angle $\square \mathrm{S}$ when it is positive is obtained as follows:

$$
\mathrm{BNI}_{\mathrm{dt}}=\frac{\mathrm{BHI} \mathrm{dt}}{\sin \left(\gamma_{\mathrm{S}}\right)} \uparrow_{\gamma s>0}
$$

For the consideration of drop shadows, [4] distinguishes the diffuse isotropic and circumsolar diffuse radiation component. This distinction is based on the developments of [2][3].

$$
\begin{aligned}
& \mathrm{DHI}_{\mathrm{dt}-\mathrm{circ}}=\mathrm{F}_{1} \times \mathrm{DHI}_{\mathrm{dt}} \\
& \mathrm{DHI}_{\mathrm{dt}-\mathrm{iso}}=\left(1-\mathrm{F}_{1}\right) \times \mathrm{DHI} d \mathrm{dt}
\end{aligned}
$$

\section{THE TOPOCENTRIC ZENITH ANGLE:}

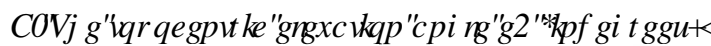

without correction of atmospheric refraction [6][7][8], is presented with this formula:

$e_{0}=\operatorname{Arcsin}\left(\sin \varphi * \sin \delta^{\prime}+\cos \varphi * \cos \delta^{\prime} * \cos H^{\prime}\right)$

Where:

H': the topocentric local hour angle.

$\delta^{\prime}:$ the topocentric sun declination.

where $i j$ is the observer geographical latitude, positive or negative if north or south of the equator, respectively. Note that the 0.99664719 number equals $(1-f)$, where $f$ is the Earth's flattening.

\section{\%ा\$ WR RLKHUFUHUFWRQFRUHFRQ}

We present the correction $\Delta e$ (in degrees) in this equation:

$\Delta=\frac{P}{1010} * \frac{283}{273+T} * \frac{1.02}{60 * \tan \left(e_{0}+\frac{10.3}{e_{0}+5.11}\right)}$

where,

- $P:$ is the annual average local pressure (in millibars).

- $T$ : is the annual average local temperature $\left(\right.$ in ${ }^{\circ} \mathrm{C}$ ).

- $e_{0}$ is the tangent argument in degrees, and then convert to radians.

\& 1 RZ UR HMP DUA WKH UHDO WRSRFHQWF

HOMDURQ DQJGH H पIQ GHUHMU ZH PXWW

FRPEIQH H DQG áH ICXWWOWG IQ UKLV

HIXDURQ

$e=e_{0}+\Delta \mathrm{e}$

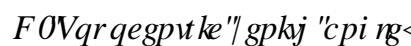

We present the zenith angle $\theta$ (in degrees), in this equation, after calculating the topocentric elevation angle $e$ with correction of atmospheric refraction:

$\theta=90-\mathrm{e}$ 


\section{THE TOPOCENTRIC AZIMUTH ANGLE:}

The azimuth angle is an essential element in solar geometry presented by $\Phi$ (in degrees), based on calculation of the astronomer's azimuth angle. The figure 1.a. show the uncertainty of cosine angle resulting from $0.01^{\circ}$ with $0.0003^{\circ}$ uncertainty $[6][7][9]$.

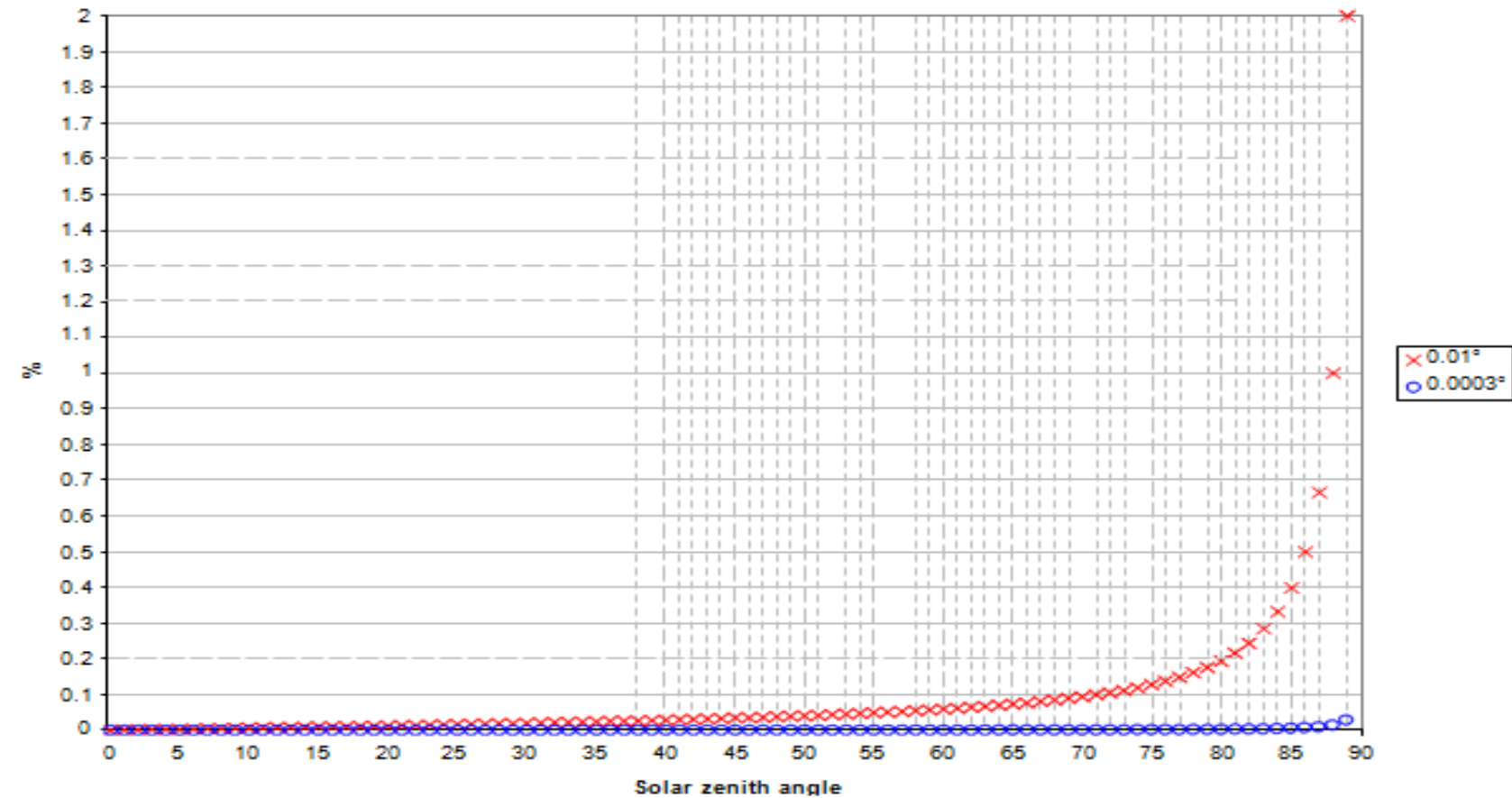

Figure 1.a. Uncertainty of cosine angle resulting from $0.01^{\circ}$ and $0.0003^{\circ}$ uncertainty (The solar zenith) [6][7][9].

\section{\$प7RSRFHQWFDWURQRP HWDIP XUKDQJ GH

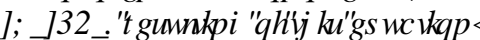

$$
\Gamma=\operatorname{Arctan} 2\left(\frac{\sin H^{\prime}}{\cos H^{*} \sin \varphi-\tan \delta^{*} \cos \varphi}\right)
$$

$\Gamma$ is measured eastward from north, and Limited from $0^{\circ}$ to $360^{\circ}$.

\section{\%円7RSRFHQMFD]IP XUKDQJ (OI}

This angle is presented by $\varnothing$ in this paper (in degrees) [11],

$\emptyset=\Gamma+180$

$\emptyset$ : vary from $0^{\circ}$ to $360^{\circ}$, and measured eastward from north.

\section{INCIDENCE ANGLE, I (IN DEGREES):}

This angle calculated for several surface oriented in any direction. It is the best way to calculate the solar orientation for the estimation of the solar energy:

$I=\operatorname{Arccos}(\cos \theta * \cos \omega+\sin \omega * \sin \theta * \cos (\Gamma-\gamma))$

where,

$-\omega$ : the slope of the surface measured from the horizontal plane.

$-\gamma$ : the surface azimuth rotation angle.

Parameter F1 is evaluated from the following expression:

$\mathrm{F}_{1}=\min \left(\max \left(\mathrm{F}_{11}(b(\varepsilon))+\Delta \mathrm{F}_{12}(b(\varepsilon))+\theta_{S} F_{13}(b(\varepsilon)), 0\right), 1\right)$

Where:

- $\theta_{\mathrm{S}}$ is the solar zenith angle complementary to the solar elevation $\gamma_{S}$

- $\Delta$ is the sky brightness index;

- $b$ is a lookup table, with input of clearness index $\varepsilon$ and returning an index in the three tables of values F11, F12 and F13.

$$
b(\varepsilon)=\left\{\begin{array}{l}
1 \text { si } \varepsilon \epsilon[1,1.065[ \\
2 \text { si } \varepsilon \epsilon[1.065,1.230[ \\
3 \text { si } \varepsilon \epsilon[1.230,1.5[ \\
4 \text { si } \varepsilon \epsilon[1.5,1.95[ \\
5 \text { si } \varepsilon \epsilon[1.95,2.8[ \\
6 \text { si } \varepsilon \epsilon[2.8,4.5[ \\
7 \text { si } \varepsilon \epsilon[4.5,6.2[
\end{array}\right.
$$

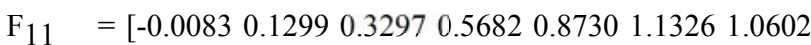
0.6777]

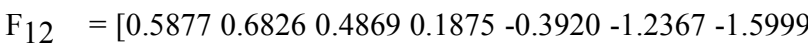
$-0.3273]$

$\mathrm{F}_{13}=\left[\begin{array}{llllll}-0.0621 & -0.1514 & -0.2211 & -0.2951 & -0.3616 & -0.4118\end{array}-\right.$ $0.3589-0.2504]$

The sky brightness index $\Delta$, for its part, is established via the following equation involving the diffuse component $\mathrm{DHI}_{\mathrm{dt}}$, the radiation outside the atmosphere at normal incidence $\mathrm{E} 0_{\mathrm{dt}}$ and the relative optical attenuation factor of the atmospheric thickness $\mathrm{m}$ (relative optical air mass factor):

$\Delta=\mathrm{m} \frac{\mathrm{DHI}_{\mathrm{dt}}}{\mathrm{EO}_{\mathrm{dt}}}$

This relative optical attenuation factor of the atmospheric thickness $\mathrm{m}$ is obtained from the solar elevation $\gamma_{\mathrm{S}}$ (expressed in radian) and the elevation of the site $\mathrm{h}$ (expressed in $\mathrm{m}$ ) by the following relation:

$m=\exp \left(-\frac{h}{8434.5}\right)\left(\sin \left(\gamma_{s}+\Delta \gamma_{s}\right)+0.50572\left(\frac{180}{\pi}\left(\gamma_{s}+\right.\right.\right.$

$\left.\left.\left.\Delta \gamma_{s}\right)\right)^{-1.6364}\right)^{-1}$

The term $\Delta \gamma_{\mathrm{s}}$ (in radian) corresponds to the correction related to the atmospheric refraction of the solar elevation according to the relation

$\Delta \gamma_{s}\left(\gamma_{s}\right)=0.0010709 \frac{0.1594+64.3432 \gamma_{\mathrm{s}}+215.5359 \gamma_{\mathrm{s}}{ }^{2}}{1+166.1257 \gamma_{\mathrm{s}}+910640.9614 \gamma_{\mathrm{s}}{ }^{2}}$ 
Finally, the sky brightness index $\varepsilon$ is determined, in turn, depending on the direct and diffuse components of the radiation and the solar zenith angle $\theta_{\mathrm{s}}$ (in radians):

$\varepsilon=\left(\frac{\mathrm{DHI}_{\mathrm{dt}}+\mathrm{BNI}_{\mathrm{dt}}}{\mathrm{DHI}_{\mathrm{dt}}}+1.041 \theta_{\mathrm{s}}^{3}\right)\left(1+1.041 \theta_{\mathrm{s}}^{3}\right)^{-1}$

All these equations thus make it possible to decompose the diffuse irradiation $\mathrm{DHI}_{\mathrm{dt}}$ into:

- Circumsolar diffuse irradiation $\mathrm{DHI}_{\mathrm{dt}-\mathrm{circ}}$;

- Isotropic diffuse irradiation DHIdt-iso.

We will explain the methods to estimate from these different irradiations on the horizontal plane, the irradiations, including that reflected by the ground, on inclined plane of azimuth $\alpha$ and tilt $\beta$, taking shading effects.

This shading effect of the environment is defined by the horizon function $Z(\varnothing)$. This function defines, for a given azimuth $\emptyset$, the zenith angle from which the sun is visible.

We note, for the rest, $\theta_{I}(\alpha, \beta)$ the angle of incidence of the direct radiation of the sun in position $\left(\alpha_{S}, \theta_{S}\right)$ where $\alpha_{S}$ designates the solar azimuth. The cosine of this angle of incidence checks the following relation:

$\cos \theta_{I}(c, \beta)=\cos \beta \cos \theta_{s}+\sin \beta \sin \theta_{s} \cos \left(\alpha_{s}-\alpha\right)$

The factor noted $R_{B}(\alpha, \beta)$ accounting the effect of the shadows [5] on the direct radiation, verifies the following relation:

$\mathrm{R}_{\mathrm{B}}(\alpha, \beta)=\frac{\sin \theta(\alpha, \beta)}{\cos \theta_{\mathrm{s}}} \uparrow\left(\theta_{\mathrm{s}}<\mathrm{Z}\left(\alpha_{\mathrm{s}}\right)\right) \uparrow\left(\cos \theta_{\mathrm{s}}>0\right) \uparrow$

$\left(\cos \theta_{I}(\alpha, \beta)>0\right)$

This factor also applies to circumsolar diffuse radiation.

The factor noted $R_{D}(\alpha, \beta)$ named sky-view factor [1] accounting for the effect on the isotropic diffuse radiation and shadows on the direct radiation, verifies the following relation:

$\mathrm{R}_{\mathrm{B}}(\alpha, \beta)=\frac{1}{\pi} \int_{\emptyset=0}^{2 \pi} \int_{\theta=0}^{\mathrm{Z}(\varnothing)} \sin \theta(\cos \theta \sin \beta+\sin \theta \sin \beta \cos (\varnothing-$ $\alpha)) \mathrm{d} \theta \mathrm{d} \emptyset$

Where :

$(X)=\left\{\begin{array}{c}X \text { si } X>0 \\ 0 \text { sinon }\end{array}\right.$

We check that if $Z(\phi)=\pi / 2$ (absence of shading effect), then, in the case of a horizontal plane, $R_{D}(\alpha, \beta=0)=1$.

For the evaluation of $\mathrm{R}_{\mathrm{D}}(\alpha)$, we are interested in the sign of $\cos \theta \sin \beta+\sin \theta \sin \beta \cos (\varnothing-\alpha)$.

since, the condition $\cos \theta \sin \beta+\sin \theta \sin \beta \cos (\varnothing-\alpha) \geq 0$ is equivalent to $\tan \theta \cos (\varnothing-\alpha) \sin \beta \geq \cos \beta$, we have two cases:

case $1: \cos (\varnothing-\alpha) \geq 0$, alors $\cos \theta \sin \beta+\sin \theta \sin \beta \cos (\varnothing-\alpha) \geq 0$

case $2: \cos (\varnothing-\alpha)<0$

Thus, for $(\cos \theta \sin \beta+\sin \theta \sin \beta \cos (\varnothing-\alpha) \geq 0)$, it is necessary that $\left(\tan \theta \leq \frac{-1}{\tan \beta \cos (\emptyset-\alpha)}\right)$.

If we note $\theta_{+}(\theta, \alpha, \beta)=\operatorname{atan}\left(-(\cos (\varnothing-\alpha) \tan \beta)^{-1}\right)$, then the condition is that $\theta \leq \theta_{+}(\theta, \alpha, \beta)$.
If more, we pose $\theta_{+}(\theta, \alpha, \beta)=\pi / 2$ when $\cos (\varnothing-\alpha) \geq 0$ et $\mathrm{Z}_{+}(\emptyset, \alpha, \beta)=\min \left(\mathrm{Z}(\emptyset), \theta_{+}(\emptyset, \alpha, \beta)\right)$, then:

$\pi \mathrm{R}_{\mathrm{D}}(\alpha, \beta)=\int_{\emptyset=0}^{2 \pi} \int_{\theta=0}^{\mathrm{Z}_{+}(\emptyset, \alpha, \beta)} \sin \theta(\cos \theta \cos \beta+$

$\sin \theta \sin \beta \cos (\varnothing-\alpha)) d \theta d \varnothing$

$=\cos \beta \int_{0}^{2 \pi}\left(\int_{\theta=0}^{\mathrm{Z}_{+}(\emptyset, \alpha, \beta)} \sin \theta \cos \theta d \theta\right) d \emptyset+\sin \beta \int_{0}^{2 \pi} \cos (\varnothing-$

$\alpha)\left(\int_{\theta=0}^{Z_{+}(\emptyset, \alpha, \beta)} \sin ^{2} \theta d \theta\right) d \emptyset$

$=\frac{1}{2} \int_{0}^{2 \pi}\left(\sin ^{2} Z_{+}(\varnothing, \alpha, \beta) \cos \beta+\cos (\varnothing-\alpha)\left(Z_{+}(\emptyset, \alpha, \beta)-\right.\right.$

$\left.\left.\sin \mathrm{Z}_{+}(\emptyset, \alpha, \beta) \cos \mathrm{Z}_{+}(\emptyset, \alpha, \beta)\right) \sin \beta\right) \mathrm{d} \emptyset$

Since $\int_{\theta=0}^{Z} \sin \theta \cos \theta d \theta=\frac{\sin ^{2} Z}{2}$ and $\int_{\theta=0}^{Z} \sin ^{2} \theta d \theta=$

$\frac{1}{2}(\mathrm{Z}-\sin \mathrm{Z} \cos \mathrm{Z})$ So, ultimately, we have:

$\mathrm{R}_{\mathrm{D}}(\alpha, \beta)=\frac{1}{2 \pi} \int_{0}^{2 \pi}\left(\sin ^{2} \mathrm{Z}_{+}(\varnothing) \cos \beta+\cos (\varnothing-\alpha)\left(\mathrm{Z}_{+}(\varnothing)-\right.\right.$

$\left.\left.\sin \mathrm{Z}_{+}(\emptyset) \cos \mathrm{Z}_{+}(\emptyset)\right) \sin \beta\right) d \varnothing$

Where:

$\mathrm{Z}_{+}(\emptyset)=\min \left(\mathrm{Z}(\theta), \theta_{+}(\emptyset, \alpha, \beta)\right)$

$\theta_{+}(\theta)=\left\{\begin{array}{c}\operatorname{atan}\left(-(\cos (\varnothing-\alpha) \tan \beta)^{-1}\right) \\ \text { si } \cos (\varnothing-\alpha)<0 \\ \pi / 2 \text { sinon }\end{array}\right.$

In the absence of shading effect,,$Z(\varnothing)=\pi / 2$ and the skyview factor checked:

$\mathrm{R}_{\mathrm{D}}(\alpha, \beta)=\frac{1+\cos \beta}{2}$

Finally, the reflected component of the irradiation, denoted RI, is defined by the following relation:

$\operatorname{RTI}_{\mathrm{dt}}{ }^{+}(\alpha, \beta)=\rho \mathrm{R}_{\mathrm{R}}(\alpha, \beta)\left(\uparrow\left(\theta_{\mathrm{s}}<\mathrm{Z}\left(\alpha_{\mathrm{s}}\right)\right)\left(\mathrm{BHI}_{\mathrm{dt}}+\right.\right.$

$\left.\left.\mathrm{DHI}_{\mathrm{dt}-\text { circ }}\right)+\mathrm{R}_{\mathrm{D}}(0,0) \mathrm{DHI} \mathrm{dt}_{\mathrm{dt}-\mathrm{iso}}\right)$

Finally, the relations below express the different components of the radiation on an inclined plane of orientation $(\alpha, \beta)$, taking into account the orography via the horizon function $Z$.

Direct radiation on an corrected inclined plane $(\alpha \square \square \beta)$ of the orography:

$\mathrm{BTI}_{\mathrm{dt}}{ }^{+}(\alpha, \beta)=\mathrm{R}_{\mathrm{B}}(\alpha, \beta) \mathrm{BHI}_{\mathrm{dt}}$.

Diffuse circumsolar radiation on an corrected inclined plane $(\alpha, \beta)$, of the orography:

$\mathrm{DTI}_{\mathrm{dt}-\operatorname{circ}^{+}}(\alpha, \beta)=\mathrm{R}_{\mathrm{B}}(\alpha, \beta) \mathrm{DHI}_{\mathrm{dt}-\operatorname{circ}}$.

Diffuse isotropic radiation on an corrected inclined plane $(\alpha \square \square \beta)$ of the orography:

$\mathrm{DTI}_{\mathrm{dt}-\mathrm{iso}}{ }^{+}(\alpha, \beta)=\mathrm{R}_{\mathrm{D}}(\alpha, \beta) \mathrm{DHI}_{\mathrm{dt}-\mathrm{i} \text { so }}$.

reflected Radiation by albedo soil $\rho$ on an corrected inclined plane $(\alpha, \beta)$ of the orography:

$\mathrm{RTI}_{\mathrm{dt}}{ }^{+}(\alpha, \beta)=\rho \mathrm{R}_{\mathrm{R}}(\alpha, \beta)\left(\mathrm{BTI}_{\mathrm{dt}}{ }^{+}(0,0)+\mathrm{DTI}_{\mathrm{dt}-\mathrm{circ}}{ }^{+}(0,0)+\right.$

$\left.\mathrm{DHI}_{\mathrm{dt}-\mathrm{iso}}{ }^{+}(0,0)\right)$.

Global radiation on an corrected inclined plane $(\alpha, \beta)$ of the orography:

$\operatorname{GTI}_{\mathrm{dt}}{ }^{+}(\alpha, \beta)=\mathrm{BTI}_{\mathrm{dt}}{ }^{+}(\alpha, \beta)+\mathrm{DTI}_{\mathrm{dt}-\operatorname{circ}}{ }^{+}(0,0)+$

$\mathrm{DHI}_{\mathrm{dt}-\mathrm{iso}}{ }^{+}(0,0)+\mathrm{RTI}_{\mathrm{dt}}{ }^{+}(\alpha, \beta)$. 

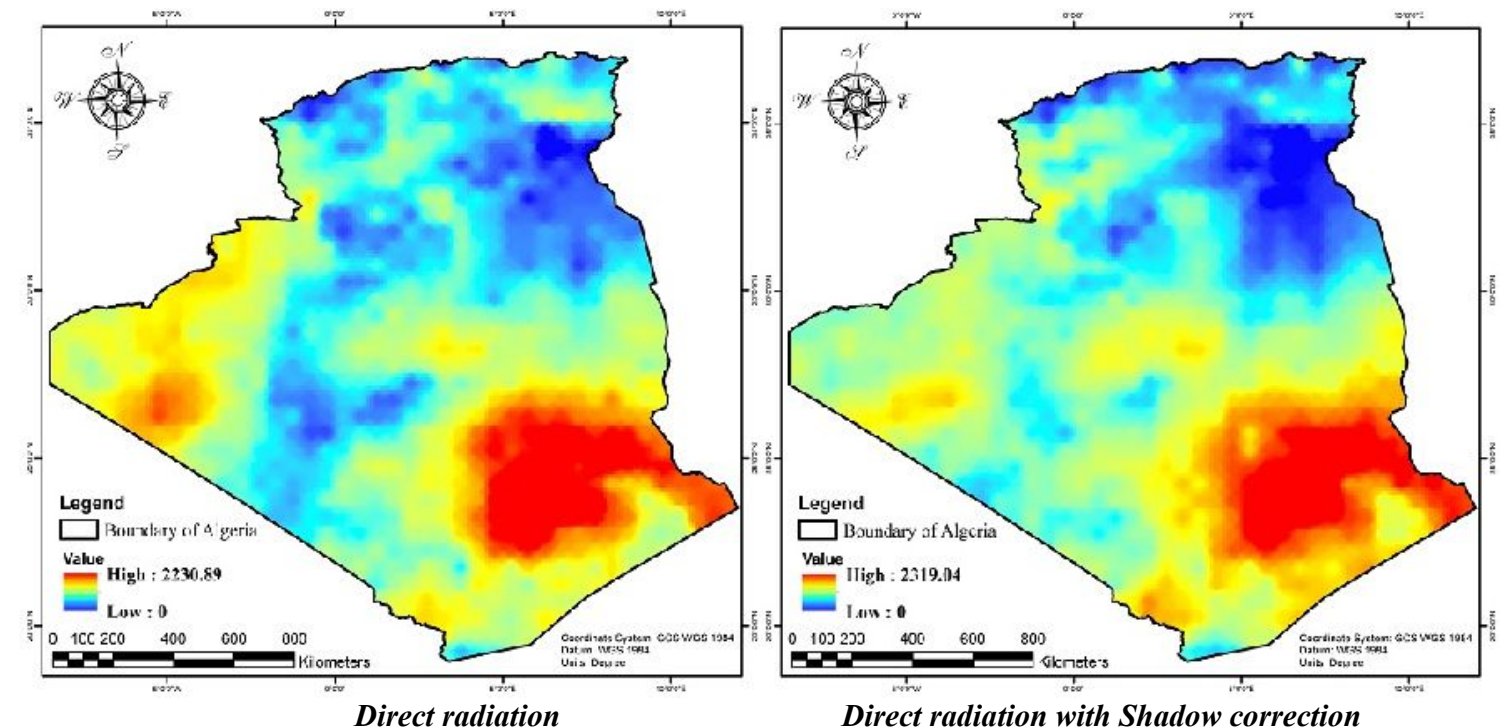

Direct radiation with Shadow correction

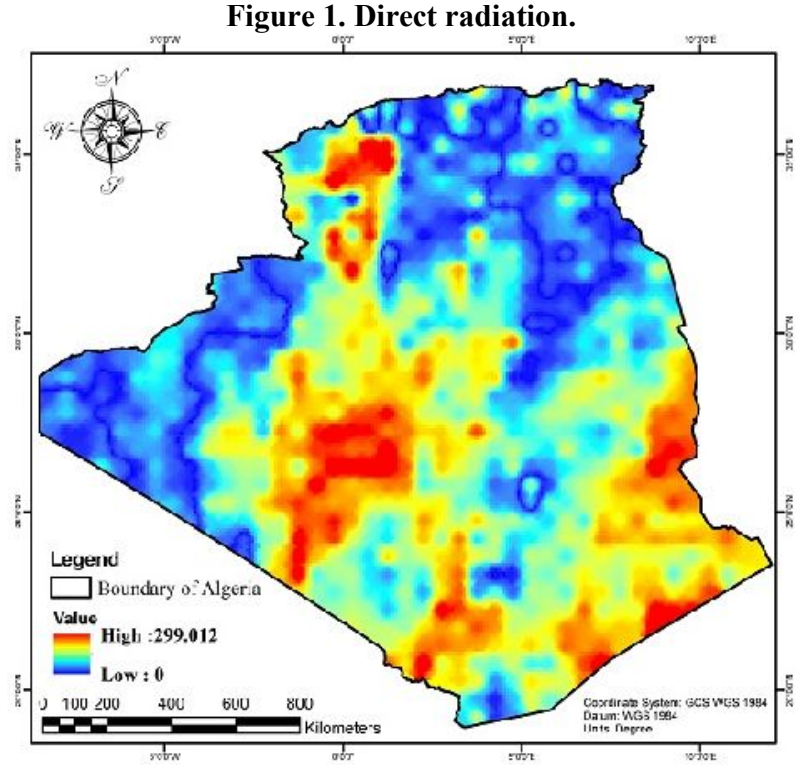

Figure 2. Difference between Direct radiation and Direct radiation with shadow correction.

The figure 1 show the direct irradiation maps on a horizontal plane $\left(\max =2230.89 \mathrm{Watt} / \mathrm{m}^{2}\right)$ and the second on an inclined plane with shadow correction $\left(\mathrm{Max}=2319.04 \mathrm{Watt} / \mathrm{m}^{2}\right)$. The difference

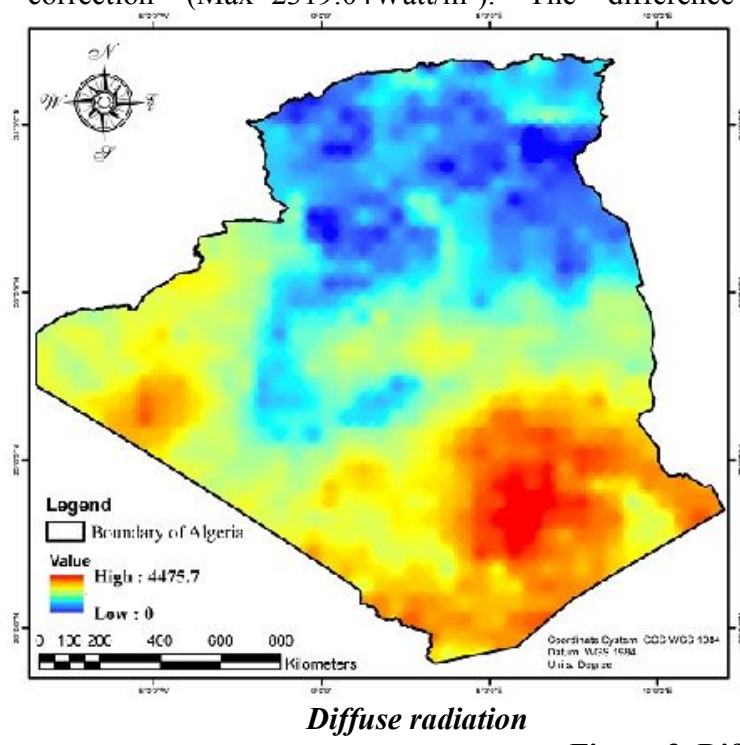

between the two results of the figure 1 is illustrated in figure 2, which shows a variation from one point to another according to the effect of the shadow, which extends to $\left(299.012 \mathrm{Watt} / \mathrm{m}^{2}\right)$.

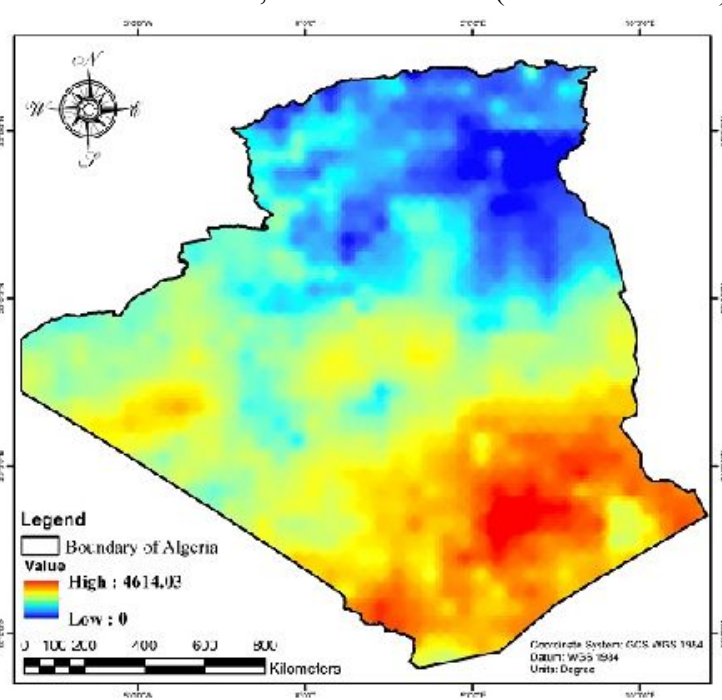

Diffuse radiation with Shadow correction

Figure 3. Diffuse radiation 


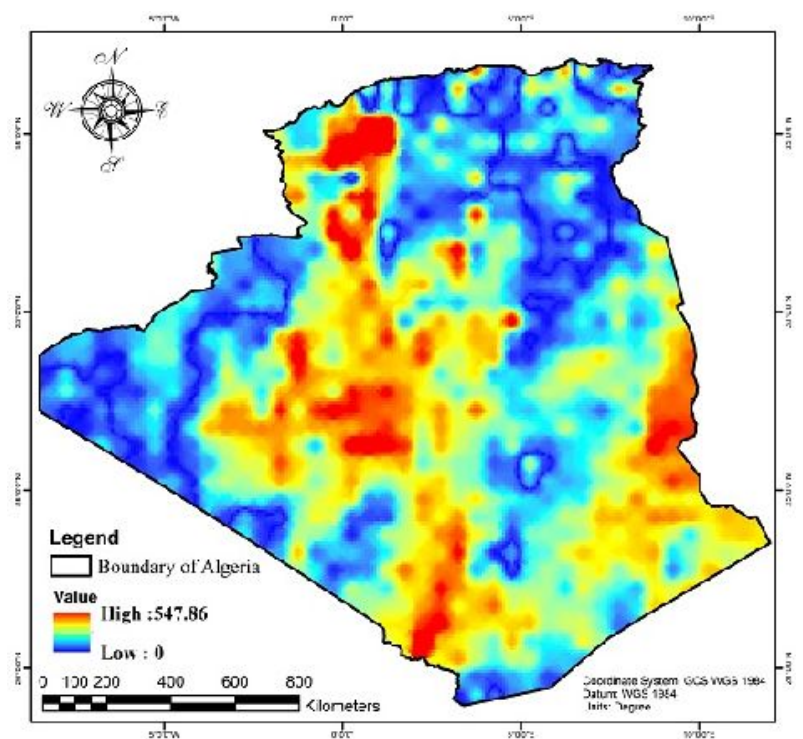

Figure 4. Difference between Diffuse radiation and Diffuse radiation with shadow correction.

The figure 3 show the diffuse irradiation maps on a horizontal plane between the two results of the figure 3 is illustrated in figure 4 , $\left(\max =4475.7 \mathrm{Watt} / \mathrm{m}^{2}\right)$ and the second on an inclined plane with which shows a variation from one point to another according to the shadow correction $\left(\mathrm{Max}=4614.03 \mathrm{Watt} / \mathrm{m}^{2}\right)$. The difference effect of the shadow, which extends to $\left(547.86 \mathrm{Watt} / \mathrm{m}^{2}\right)$.
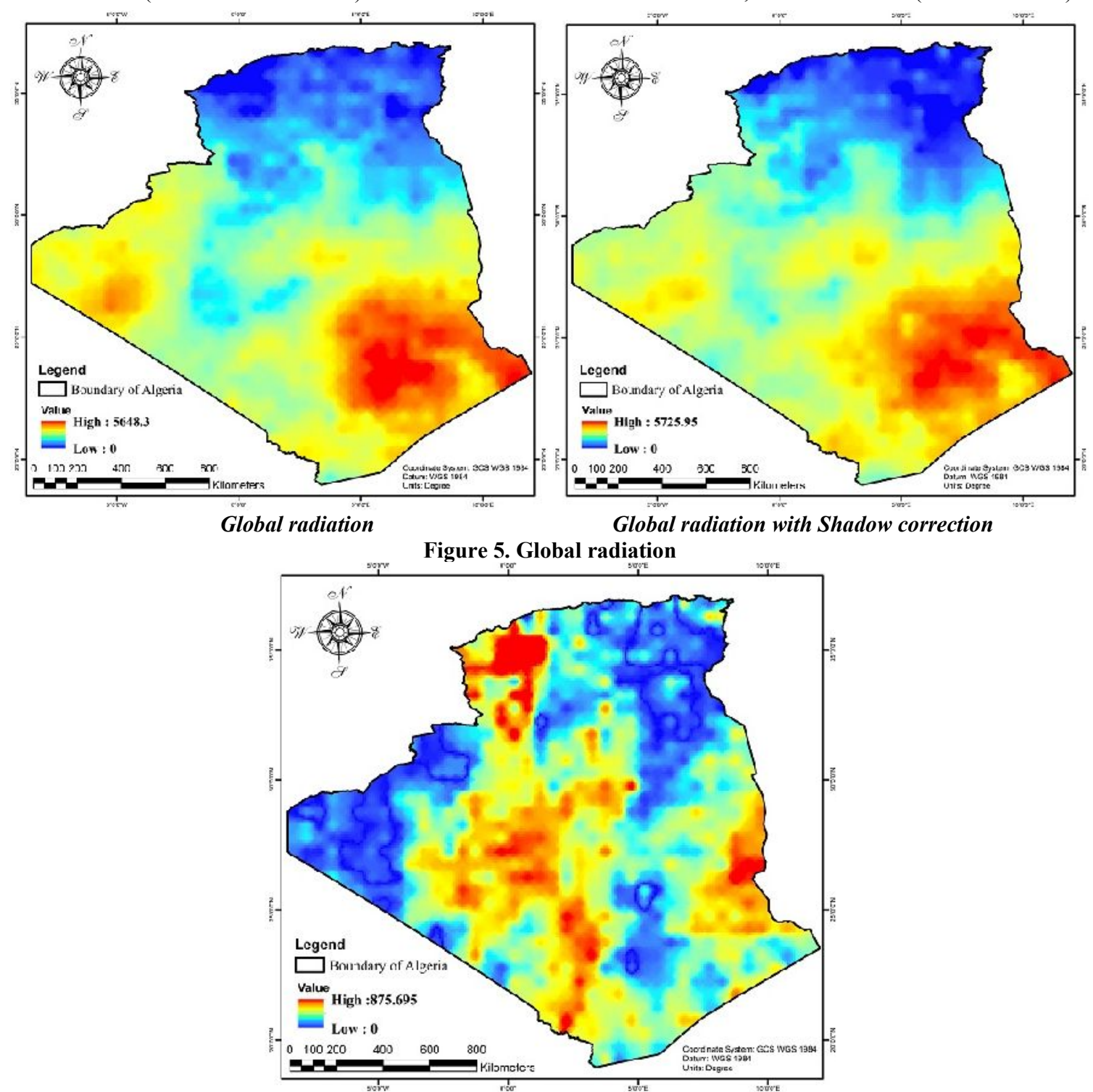

Figure 6. Difference between Global radiation and Global radiation with shadow correction. 
The figure 5 show the global irradiation maps on a horizontal plane To validate the results of our algorithm, we selected 5 random $\left(\max =5684.3 \mathrm{Watt} / \mathrm{m}^{2}\right)$ and the second on an inclined plane with points on the surface of Algeria mentioned in the figure 7. and we shadow correction $\left(\mathrm{Max}=5725.95 \mathrm{Watt} / \mathrm{m}^{2}\right)$. The difference extracted the results of the different components (Direct, Diffuse, between the two results of the figure 5 is illustrated in figure 6, Gobal) for the analyzed and to prove the robustness of the algorithm which shows a variation from one point to another according to the used. The 5 points illustrated on the table 1 . effect of the shadow, which extends to $\left(875.695 \mathrm{Watt} / \mathrm{m}^{2}\right)$.

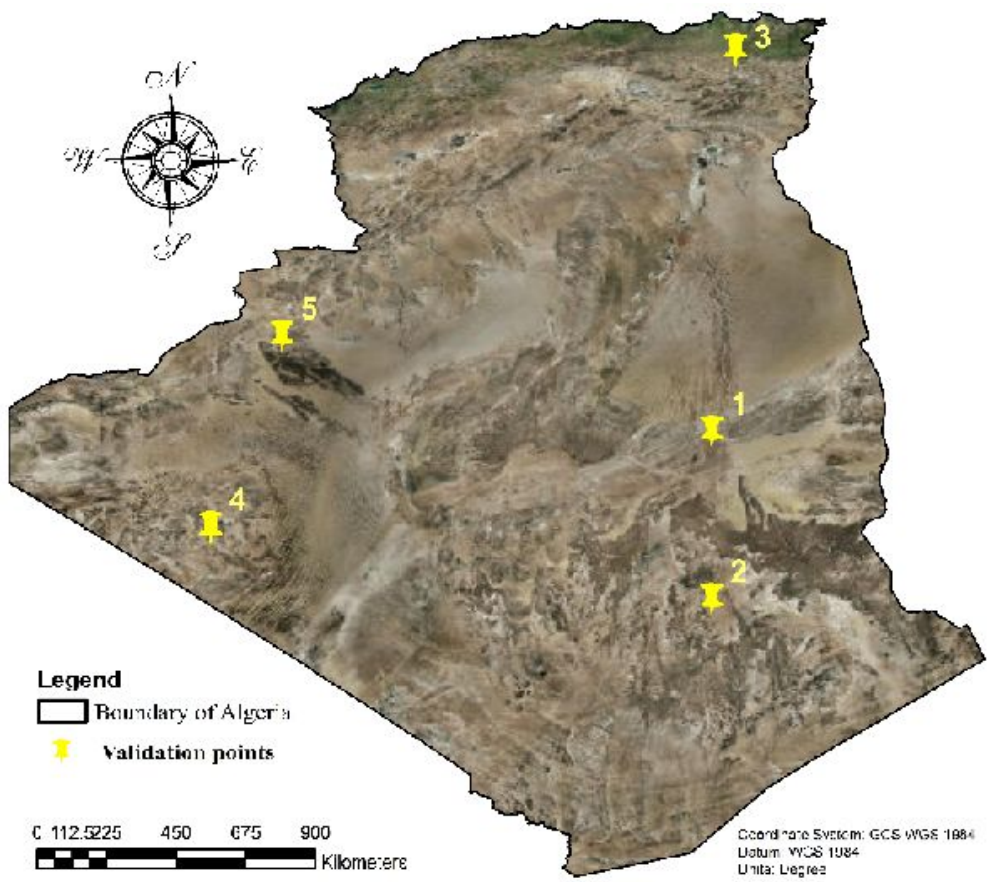

Figure 7. The selection of 5 random points on the surface of Algeria for the validation of the results.

\begin{tabular}{|c|c|c|c|c|c|}
\hline & $\begin{array}{l}\text { Radiation without } \\
\text { Shadow correction }\end{array}$ & $\begin{array}{c}\text { Radiation with shadow } \\
\text { correction }\end{array}$ & & Longitude & Latitude \\
\hline P1 & $\begin{array}{l}3668,180071 \\
1625,387337 \\
4494,798612 \\
\end{array}$ & $\begin{array}{r}3442,766777 \\
1502,090162 \\
4176,582265 \\
\end{array}$ & \begin{tabular}{|l} 
Diffuse \\
Direct \\
Global \\
\end{tabular} & 6,25 & 28,25 \\
\hline $\mathrm{P} 2$ & $\begin{array}{l}4272,588034 \\
2049,395888 \\
5398,851398\end{array}$ & $\begin{array}{l}4143,925671 \\
1932,513822 \\
5120,612264\end{array}$ & \begin{tabular}{|l|} 
Diffuse \\
Direct \\
Global
\end{tabular} & 6,25 & 24,75 \\
\hline P3 & $\begin{array}{l}3128,689006 \\
1424,765313 \\
3154,785191 \\
\end{array}$ & $\begin{array}{c}3128,613617 \\
1422,605655 \\
3083,32719 \\
\end{array}$ & $\begin{array}{l}\text { Diffuse } \\
\text { Direct } \\
\text { Global } \\
\end{array}$ & 6,75 & 36,25 \\
\hline $\mathrm{P} 4$ & $\begin{array}{l}3915,427897 \\
1731,899578 \\
4686,937173 \\
\end{array}$ & $\begin{array}{c}3870,776444 \\
1738,160973 \\
4695,08481 \\
\end{array}$ & $\begin{array}{l}\text { Diffuse } \\
\text { Direct } \\
\text { Global } \\
\end{array}$ & $-4,25$ & 26,25 \\
\hline P5 & $\begin{array}{l}3523,025023 \\
1593,273982 \\
4234,265222\end{array}$ & $\begin{array}{c}3632,173707 \\
1646,494099 \\
4348,45375\end{array}$ & \begin{tabular}{|l|} 
Diffuse \\
Direct \\
Global
\end{tabular} & $-2,75$ & 30,25 \\
\hline
\end{tabular}

Table 1. Presentation of the 5 points on the three components (Direct, Diffuse, Global) on a horizontal plane and it evaluation on inclined plane with shadow correction.

The figures $(1,2,3,4,5$ and 6$)$ show the difference between the shadow correction, estimated to (R2=0.9141 in global radiation radiation on a horizontal plane and its evaluation on any inclined plane, according to an integration period between t-dt and $t$ of a single day by the use of the real satellite data as input for the system. The figures (2,4 and 6) show the difference brought by the correction of the shading effects for the irradiation estimated on a horizontal plane and its evaluation on corrected inclined planes, where the results found are very satisfactory, whose graphs in figure $(8,9,10,11,12,13)$ show a very good correlation between the three components (Direct, Diffuse, Global) of solar irradiation on a horizontal plane and its evaluation on the inclined plane with the

with all points and R2=0.9998 for each point separately.).

These figures show that orography is a major factor influencing the spatial variability of solar irradiation in the same way in figures $(2,4$ and 6) on the three components (Direct, Diffuse and Global). The shadows cast by topographies, the slope and aspect and the variation in altitude all affect the amount of solar irradiation received in different locations.

the trend estimate for all the points presented in Figure 7 gave a good result of $R 2=0.9141$ in Figure 8 for the estimated global radiation component. 


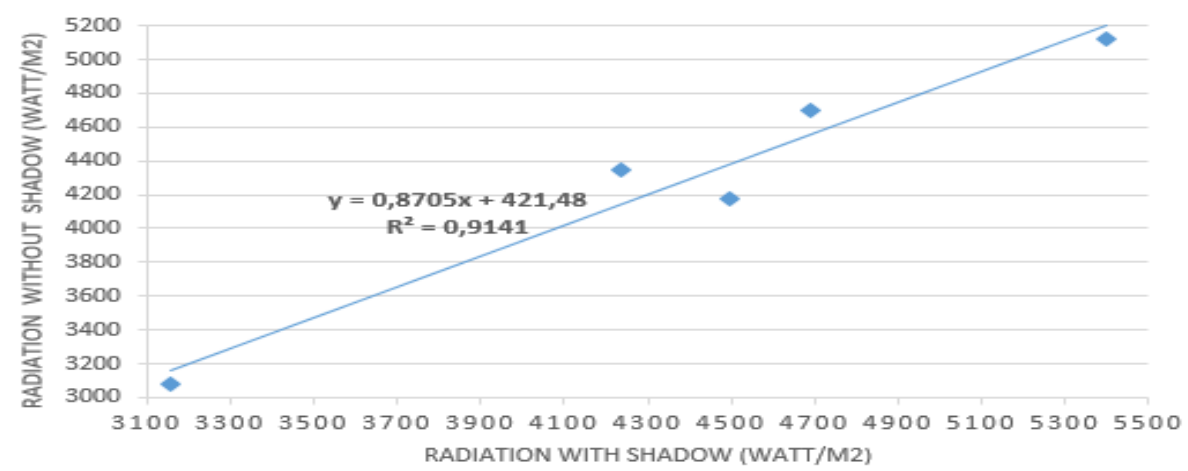

Figure 8. Validation results of the estimated Global irradiation of the model under horizontal plane conditions and corrected inclined plane $X$ of the orography with correction of shading effects on different components of radiation.

The trend function calculates for the data shown in Table 1 showed Table 1 showed very perfect results, which means that there is a very perfect results $\left(\mathrm{R}^{2}=0.9998\right)$ in all the following figures very good consistency between the three components for the 5 $(9,10,11,12,13)$, the trend function compute for the data shown in points used.

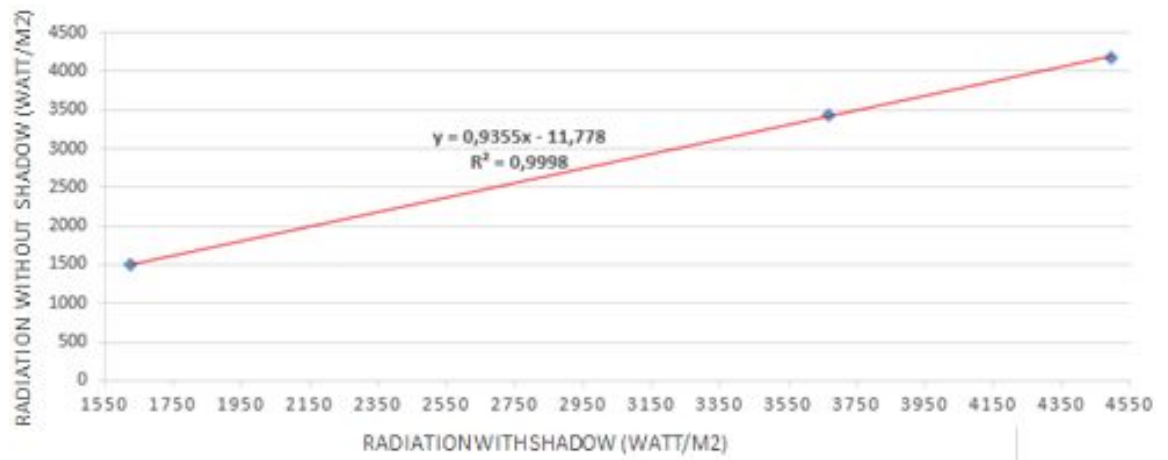

Figure 9. Trend graph to calculate the coherence between the three irradiation components

(Direct, Diffuse, Global) for the $1^{\text {st }}$ Point.

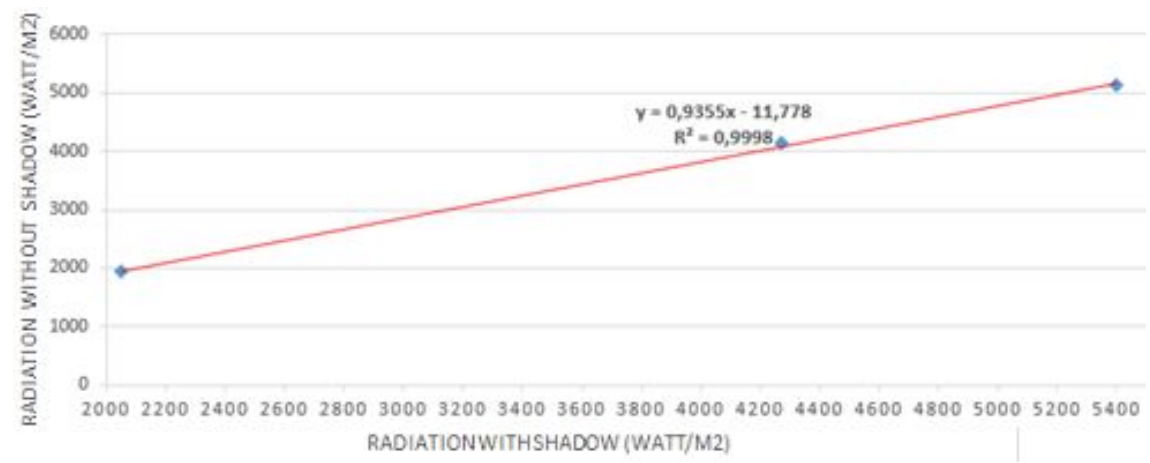

Figure 10. Trend graph to calculate the coherence between the three irradiation components

(Direct, Diffuse, Global) for the $2^{\text {nd }}$ Point.

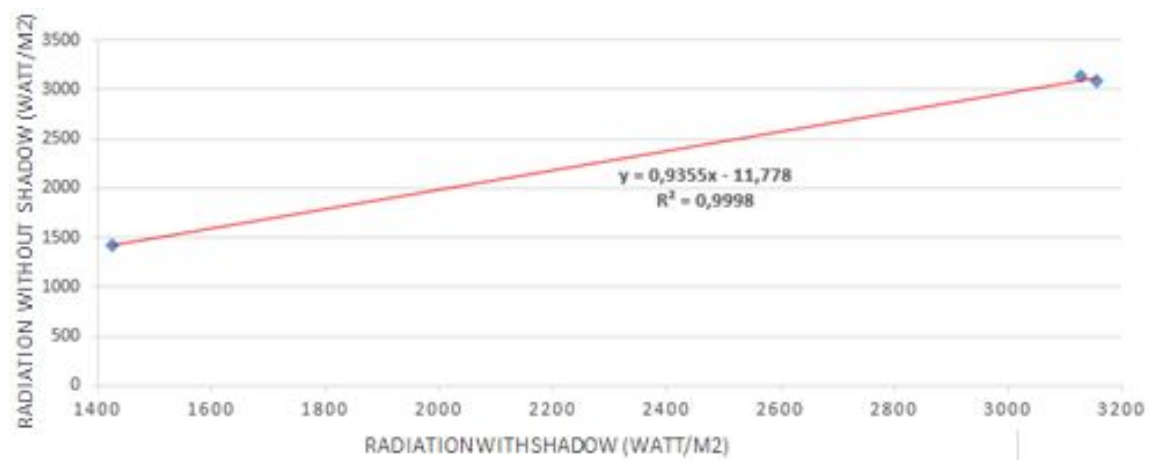

Figure 11. Trend graph to calculate the coherence between the three irradiation components

(Direct, Diffuse, Global) for the $3^{\text {rd }}$ Point. 


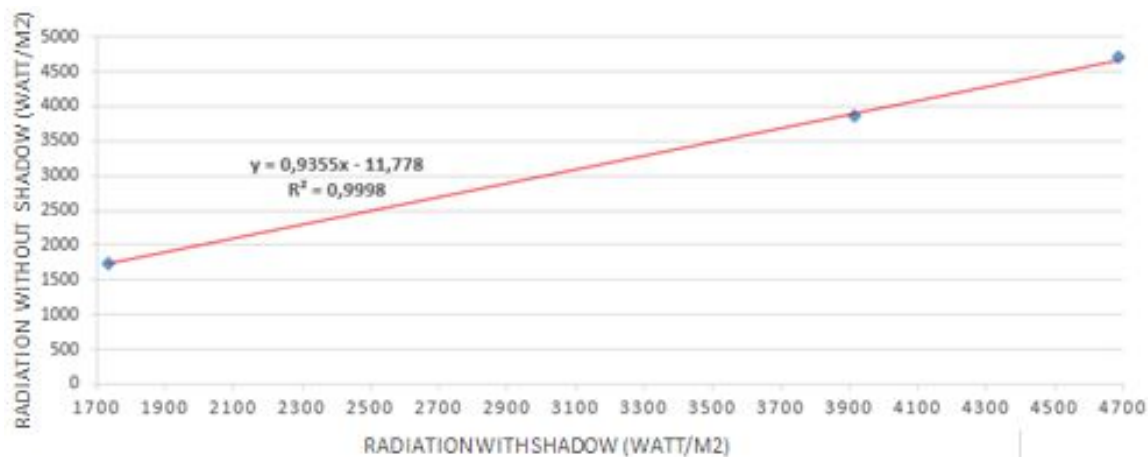

Figure 12. Trend graph to calculate the coherence between the three irradiation components (Direct, Diffuse, Global) for the $4^{\text {th }}$ Point.

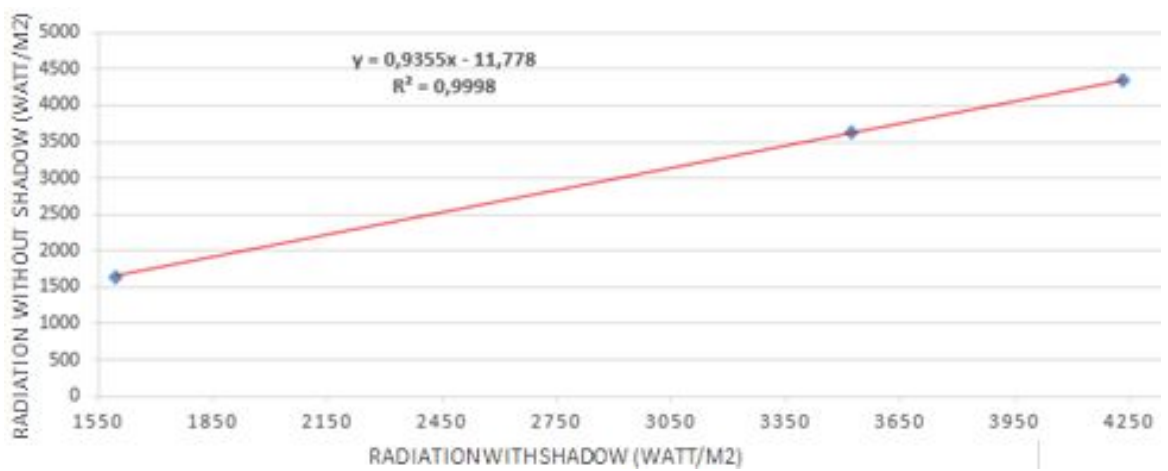

Figure 13. Trend graph to calculate the coherence between the three irradiation components (Direct, Diffuse, Global) for the $5^{\text {th }}$ Point.

Surface solar radiation shows a certain trend at the global scale in by satellite images, which are very well illustrated on the graphs in terms of spatial and temporal variations. Theoretically, the total figure 8,9,10,11,12 and 13 .

surface solar radiation absorbed by land surfaces is always greater The following windows in Figure 14 translate the atmosphere in low-latitude areas than in high-latitude areas, while the radiation diffuse irradiance, global radiance, global inclined, global level progressively decreases toward the polar regions, which horizontal radiation, Direct Inclined, Direct Horizontal, Direct shows the figures 1,3 and 5. Considering the shading effects, clouds Normal, and estimated for only one point in water for visible and other factors, this trend has been verified under real conditions band $(0.3-4 \mu \mathrm{m})$.

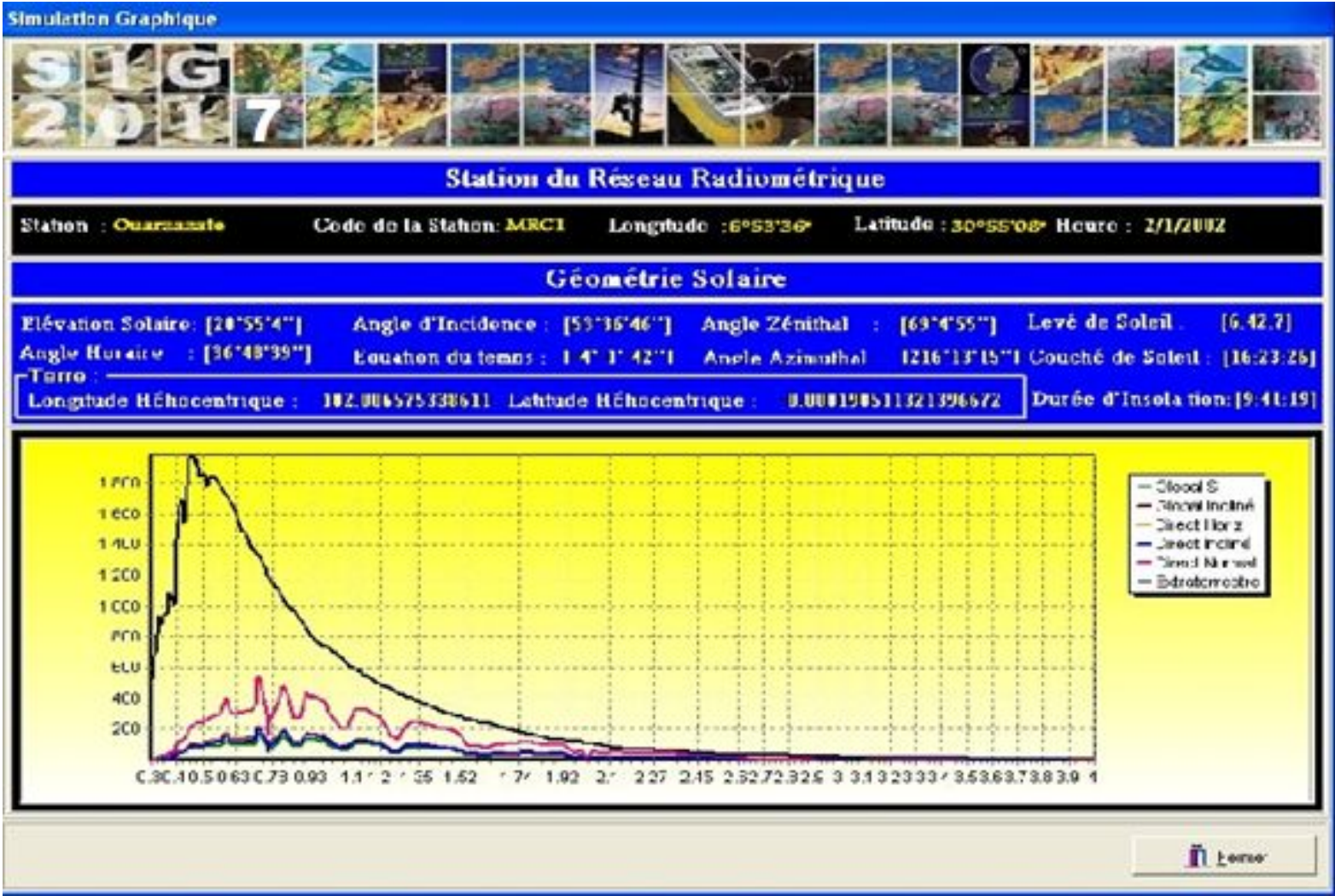

Figure 14. The Direct, Diffuse and Global irradiation for only one point in water. 


\section{CONCLUSION:}

The correction of shading effects related to the orography is a very sensitive step, that we must treat it carefully to have a good result on different component of radiation incident on the ground. The application of our approach gave better results in the different tests on the different sites. Our approach leads to applying algorithm based for correcting shading effects related to the orography estimated in Horizontal Plane and evaluate it on any inclined plane with the different attenuations. The solar irradiation has been calculated in combination satellite images data that shows good results on figure $1,2,3,4,5$ and 6 , this is the highlight of this approach which was proved by the trend function $\left(\mathrm{R}^{2}=0.9998\right)$ between the three components, shown in the figures $9,10,11,12$ and 13 .

It should be noted that the results of this sizing are conditioned by the basic parameters (meteorological and consumption profile), that they must be at the same instant before the interpolation of the data on the whole band of the visible and its integration.

\section{REFERENCE:}

[1] Dozier, J., J. Frew. 1990. Rapid calculation of terrain parameters for radiation modeling from digital elevation dam. IEEE Transactions on Geoscience and Remote Sensing, 28:963-969.

[2] Perez, R., P. Ineichen, E.L. Maxwell, R. Seals, A. Zelenka, 1992. Dynamic global to direct irradiance conversion model. ASHRAE Transactions Research Series, 354-369.

[3] Perez, R., P. Ineichen, R. Seals, J. Michalsky, R. Stewart, 1990. Modelling daylight availability and irradiance components. Solar Energy, 44:271-289.

[4] Ruiz-Arias, J. A., 2009. Modelization of the terrain's morphology influence on the solar radiation field at the Earth's surface. Doctoral thesis. University of Jaén. April 2009. 202 pp.

[5] Ruiz-Arias, J.A., H. Alsamamra, J. Tovar-Pescador, D. Pozo-Vázquez, 2010. Proposal of a regressive model for the hourly diffuse solar radiation under all sky conditions. Energy Conversion and Management, 51: 881- 893 .

[6] Blanco-Muriel, M., et al. "Computing the Solar Vector". Solar Energy. Vol. 70, No. 5,2001; pp. 431-441, 2001, Great Britain.

[7] Michalsky, J. J. "The Astronomical Almanac's Algorithm for Approximate Solar Position(1950-2050)". Solar Energy. Vol. 40, No. 3, 1988; pp. 227-235, USA.

[8] The Astronomical Almanac. Norwich:2004.

[9] Meeus, J. "Astronomical Algorithms". Second edition 1998, Willmann-Bell, Inc.,Richmond, Virginia, USA.

[10] Bernier S, Duthoit S, Ladet S, Baudet D (2014) Les concepts de base des systèmes d'information géographique(SIG) : les données et les fonctions générales. Le Cahier des Techniques de l'INRA, $\mathrm{N}^{\circ}$ spécialGéoExpé. pp. 19-26.

[11] The U.S. Naval Observatory. Washington, DC, http://www.usno.navy.mil/.

\section{Creative Commons Attribution License 4.0 (Attribution 4.0 International, CC BY 4.0)}

This article is published under the terms of the Creative Commons Attribution License 4.0 https://creativecommons.org/licenses/by/4.0/deed.en_US 